and influential member of parliament. At one time he held a seat in the cabinet. From both positions, as a savant and as a statesman, he is entitled to speak upon the relations of government to science. It is interesting to note that the princiciples which he defends were uttered by Prirce Albert in his address at Aberdeen in 1859, and long before by George Washington in his farewell address. Prince Albert laid down the doctrine that Science should "speak to the State, like a favored child to its parent, sure of his paternal solicitude for its welfare," and also " that the State should recognize in Science one of the elements of its strength and prosperity, to foster which the clearest dictates of self-interest demand." The words of Washington hardly need to be quoted to American readers :- " Promote as an object of primary importance institutions for the general diffusion of knowledge. In proportion as the structure of a government gives force to public opinion, it is essential that public opinion should be enlightened."

Sir Lyon Playfair goes back to the Greeks and the Arabs, to remind his hearers that in ancient as well as modern times the encouragement of science has been a duty of statecraft, and with many an intermediate allusion he comes to the actual state of affairs in the United Kingdom,-where the working classes now show a respect for science by selecting as their candidates for parliament in the next election such men as Professors Stuart, Roscoe, Maskelyne and Rücker. Playfair has himself received invitations from working-class constituencies in a dozen of the leading manufacturing towns.

In confirmation of the views which he advocates, Playfair refers to the action of France and Germany, and in still more emphatic terms to the practice of the United States. In some respects, he says, this young country is in advance of all European states in joining science to its administrative offices. He points particularly to the excellent work of the U. S. fish commission; and makes this amusing comparison of the English and American methods of promoting fisheries. In England there are expensive commissions to visit the coast and question the fishermen; and the fishermen, having only a knowledge of a small area, give the most contradictory and unsatisfactcry evidence. "In America, the questions are put to nature and not to fishermen,"- and the results of the inquiry are therefore far more fruitful. In this bright antithesis-questioning nature, not the fishermen-there is a ready answer to those who wish for 'practical' science, not abstract science. It seems 'practical' to question fishermen; the process proves to be fallacious. It seems ' abstract' to question nature; but this method is found to be the surest road to positive knowledge, and hence to the best results.

\section{THE EXPLOSION AT FLOOD ROCK}

Thie scientific as well as the general public has felt no little interest in the explosion which occurred on last Saturday at New York, through the effects of which one of the most dangerous obstructions to the East River passage was so altered in its conditions as to be removable in the near future. The destruction of Hallett's Point reef in 1876 was a notable exhibition of engineering skill in the use of explosives, and by its complete success gave confidence to General Newton and his aides in their attack upon Flood Rock, which, in the area undermined and in the amount of explosive material made use of, far exceeded the reef at Hallett's Point. The methods of procedure in the latter case were, in general, similar to those of the former, the two operations differing more in magnitude than in anything else.

On the occasion of the explosion of 1876 it was observed that, although in the immediate vicinity of Hallett's Point no very violent or destructive disturbance took place, the resulting earth-tremor was noticeable over an area several miles in radius. Some observations were made at that time to determine the velocity of transmission of the seismic wave, under the direction of General Abbott of the Engineer corps. The results obtained indicated a much greater speed of transmission than had been previously admitted for such disturbances, and they received considerable criticism at the hands of well-known seismologists. The explosion of last Saturday offered an opportunity for a repetition of these experiments on a greater scale and under circumstances much more favorable, as it was fair to assume that the earthtremor would be perceptible at a much greater distance from the origin of the disturbance, and that thus not only would certain errors of observation become of less importance, but any marked variation of velocity with distance would be detected.

A line of points for time observations was established by General Abbott on Long Island, which were connected, it is understood, with each other and with the point from which the mine was fired, by telegraph.

As stated in the last number of this journal, arrangements to secure observations were made by 
the U. S. geological survey, together with representatives from the naval observatory and the signal service. Although the results of this work cannot be definitely ascertained for at least some weeks, the readers of Science will doubtless be interested in a brief account of the methods of doing it.

Doubtless the most certain method of detecting slight earth-tremors is by means of a vessel of mercury, from the surface of which is reflected light from a series of pin-holes in an opaque sheet of metal or card-board, the image of the holes being observed and studied by means of a telescope properly secured against accidental disturbances. The slightest ripple in the mercury produces a blurring of the image of the small pinholes. Of course in an astronomical observatory the reflected image of a star or of illuminated micrometer lines will be equivalent to the above arrangement, and in some respects superior to it. By increasing the magnifying power, the sensitiveness of this method of observation may be increased almost indefinitely, easily being carried beyond what is desirable. A serious objection to it, however, is that the disturbance makes no record of itself, requiring, therefore, constant attention from the observer during the entire period covering the possible arrival of the wave to be detected. The great convenience of the method and the ease with which it can be used at most astronomical observatories, taken in connection with its great sensitiveness, justified the sending of circulars inviting co-operation to directors of observatories within the possible radius of appreciable disturbance. These were issued a week before the explosion, and, on the night previous to its occurrence, telegrams were sent to those who had indicated a disposition to co-operate, informing them of the exact hour fixed for the event.

The party proceeding from Washington, consisting of Professor F. W. Clarke, Professor H. M. Paul and the writer, in addition to being provided with the necessary apparatus for mercury observations, carried three seismoscopes and one chronograph, together with a number of chronometers.

The seismoscopes were of a form recently designed in the physical laboratory of the U. S. signal service, and were constructed by $\mathrm{Mr}$. Kübel, the mechanician of the geological survey. They were hastily prepared for this expedition, and have not yet quite reached their final form, but a brief description of one may be of interest.

A steel wire about two millimetres in diameter is bent so as to form a loop at the end about eight cm. in length and twelve $\mathrm{mm}$. in breadth, the sides parallel and the ends round; from one end a long needle of the same wire projects, its length being three or four times that of the loop, and its point very sharp. A cylindrical iron weight, of one or two kilos, has a hole drilled through it along the axis, large enough to freely pass the looped end of the needle, one part of this hole being of somewhat smaller diameter than the other. A small circular steel plate, with opposite sides cut away, fits the larger bore and rests on the shoulder of the smaller. Through the centre of this plate a steel screw passes downwards, the point of which rests in a small cup made in the centre of the round end of the loop, from which the needle projects. The upper end of the loop reaches a short distance through the cylindrical weight, and hangs upon a small hook rigidly secured to the cast-iron support. When in position, the steel points, on which the weight is supported, are sufficiently above the centre of gravity to insure stability. It is easily seen that this point is approximately that about which instantaneons rotation of the needle takes place when the system is slightly disturbed, and that any motion of the sustaining hook is greatly magnified at the point of the needle. Just below the latter is a sort of lever-trigger, moving freely about a horizontal axis, from the short end of which projects in a vertical direction a very fine wire two or three $\mathrm{mm}$. in length. To the long arm of the lever is fastened a platinum wire shaped like an inverted $U$, with the legs resting in mercury cups. The instrument is ' set' by lifting the long arm until the fine wire at the end of the short arm rests on the point of the projecting needle, in which position it remains with the platinum wire out of the cups and the circuit broken. A slight jar produces motion in the needle, releasing the short wire and allowing the long arm of the lever to drop and close the circuit. The instrument may be made as sensitive as is desired by diminishing the size of the needle point and of the small wire which rests upon it. The advantage of an instrument of this kind is obviously its automatic operation. It can be joined up with a chronograph and left to register its drop without further attention.

One of these seismoscopes was thus connected with a chronograph in the basement of one of the buildings belonging to the Emigrant's hospital on Ward's Island. No better point could have been found, as it was in full view of and almost the nearest point on land to Flood Rock. The writer must express his indebtedness to Dr. Marple, the physician in charge, and to others connected with the hospital, for the generous manner in which all facilities at hand were placed at his disposal in the a rrangement of this station. A mercury observa- 
tion was also made at this place and a stop-watch record was taken by Professor Clarke.

Professor Paul established himself with a mercury apparatus on Staten Island, about fifteen miles away. Professor Hallock, of the geological survey, who joined the party at New York, occupied a station at Yonkers, distant about ten miles, where he was fortunate in securing the co-operation of Mr. Thomas Ewing, Jr., of Columbia college. Mr. Hallock observed with a mercury apparatus and chronometer ; and Mr. Ewing used a seismoscope, noting the time of the 'drop' by a stop watch. Professor Rees of Columbia entered enthusiastically into the work, and used a seismoscope with a chronograph and a mercury apparatus with chronometer at the college observatory. It was planned to place an observer at the meteorological observatory in Central park, opportunity for which had been kindly offered by Dr. Draper, but at the last moment no one was available for that point. Dr. Draper, however, made a number of interesting observations on the behavior of his self-registering meteorological instruments, getting a record of the shock from nearly all of them. Astronomical observatories in the vicinity of New York had been notified; and, in a number of them, observers were anxiously awaiting the appearance of the ripple on the surface of the mercury.

Unfortunately the firing of the mine was delayed nearly fourteen minutes. This, however, did not prevent good observations at several points. From Ward's Island the movements of the men on Flood Rock were easily noted, and the observer was not obliged to begin his watch until the last steamer had left the rock, and it was known that the explosion could be expected very soon.

It is impossible to describe the appearance of the river an instant after the mine was fired. A mass of water covering several acres seemed to have been instantly lifted to a height variously estimated at from one hundred to two hundred and fifty feet. It has been several times described as resembling a gigantic iceberg; and for a moment no more fitting term could have been applied. The seismoscope left its record of the initial disturbance on the chronograph sheet, and behaved throughout in a most satisfactory manner.

At Yonkers, in spite of a prolonged observation, covering about eighteen minutes, the wave was ' caught' by both the mercury dish and the seismoscope, the times observed agreeing within onefourth of a second. The seismoscope used by Professor Rees and his assistant, Mr. Jacobi, at Columbia college, recorded the passage of several railway trains before the explosion occurred; but it was always reset, and did its work promptly when the time arrived. The long delay was the cause of a failure at the Staten Island station, occupied by Professor Paul. He recorded in his notebook a disturbance of the mercury at about three minutes past eleven, but expressed his doubt as to its being due to the explosion. After waiting six or eight minutes, he decided that this disturbance was genuine, or that the explosion had occurred and had failed to reach him, and ceased his observations. It is greatly to be regretted that $a$ record was not secured on Staten Island, as it would unquestionably have been, had the event occurred within a reasonable linit of the moment previously fixed. Observers at astronomical observatories away from New York have not yet, been directly heard from, but it is feared that the delay of fourteen minutes prevented observations: being made at many points where the wave might be expected to make itself felt. The telegraph reports an observation at New Brunswick, which was doubtless, like Professor Paul's, due to some. other cause, and which prevented the observer from afterward getting the true wave. But report comes in the same way that Professors Young, Rockwood, and McNeill, were entirely successful at Princeton. Altogether it is believed that a sufficient number of reliable observations will be reported to be of great value, and the results of their reduction will be looked for with much interest.

It is not likely that another opportunity of this. kind will occur in the near future; but from the experience of this occasion it is easy to see the importance of having the origin of the disturbance surrounded by a considerable number of stations at varying distances, at each of which a seismoscope with chronograph is used, so that where possible the record may be automatic; and it would also be extremely desirable to arrange that those in charge of the firing should agree to some plan, by means of which if the explosion did not occur at a definite hour previously announced, it. should be postponed for ten minutes, and if not then ready, for another ten, and so on. In this way observers at a distance would be almost certain of success.

It ought to be added that the work of planning and arranging for the observations above noted was necessarily hurried, that it was undertaken and carried out under circumstances by no means favorable, and that it falls far short of what was desired and hoped for by those engaged in it.

T. C. Mendenhall.

\section{DISINFECTION.}

DISINFECTION consists in the destruction of something infectious, and we fail to see any justification for the popular use of the term which makes, 